\title{
Perawatan Metode Kanguru (PMK) dapat mempercepat proses penyapihan penggunaan High Flow Nasal (HFN) pada bayi prematur
}

\author{
Nining Caswini ${ }^{1}$, Yeni Rustina ${ }^{2}$, Devi Efendi ${ }^{3,4^{*}}$ \\ ${ }^{1}$ PJ Rawat Khusus, RSUPN Cipto Mangunkusumo, Indonesia \\ 2,3 Departemen Keperawatan Anak, Fakultas IImu Keperawatan, Universitas Indonesia, Indonesia \\ ${ }^{4}$ Ners Spesialis Anak, Neonatal Intensive Care Unit (NICU), Rumah sakit Universitas Indonesia, Indonesia \\ *Coresponding Author: defiefendi@ui.ac.id
}

\begin{abstract}
Abstrak
Pendahuluan: Alat bantu napas seperti heated humidified high flow nasal (HHHFN) merupakan alat bantu napas yang sering digunakan pada bayi prematur. Tujuan penelitian ini adalah untuk mengidentifikasi penerapan perawatan metode kanguru (PMK) pada bayi prematur yang terpasang HHHFN dan dampaknya terhadap lama pemakaian HHHFN. Metode: Quasy experiment pre-post design dilakukan pada 44 bayi yang terbagi menjadi 22 bayi untuk kelompok intervensi dan 22 bayi untuk kelompok kontrol. Kriteria inklusi meliputi usia gestasi >28-36 minggu, berat badan bayi antara $>1000-2500$ gram, dan terpasang alat bantu napas HHHFN. Hasil: Terdapat perbedaan bermakna antara kelompok intervensi dan kelompok kontrol terhadap perlakuan PMK dan lama pemakaian HHHFN dengan nilai $p=0,001 ; a<0,05$. Simpulan: Hasil penelitian mengidentifikasi bahwa penerapan PMK pada bayi prematur yang terpasang alat bantu napas HHHFN dapat mempercepat proses weaning jika dibandingkan dengan bayi yang tidak dilakukan PMK $(p<0,001)$. Oleh karena itu, perawat yang bertugas di ruang perawatan neonatus perlu menerapkan PMK pada neonatus yang terpasang HHHFN agar bayi dapat menurunkan lama pemakaian HHHFN dan menurunkan lama rawat di rumah sakit.
\end{abstract}

Kata kunci: Bayi prematur; heated humified high flow nasal; perawatan metode kanguru

\section{Kangaroo Mother Care Could Accelerate High Flow Nasal Weaning Process in Preterm Infants}

\begin{abstract}
Introduction: Heated humidified high flow nasal (HHHFN) has been using commonly as breathing management in preterm newborn. The purpose of this study is to identify the impact of kangaroo mother care (KMC) on the duration of HHHFN use in preterm infants. Methods: Quasy experiment with pre-post design was applied to 44 infants who were divided into intervention and control group (22 infants respectively). The inclusion criterias are: gestational age > 28-36 weeks, infant weight $>1000-2500$ grams, and used HHHFN as breathing device. Results: Adaptation of interaction between intervention and control group on PMK treatment and duration of using HHHFN with $\mathrm{p}$ value $=0.001 ; \mathrm{a}<0.05$. Conclusions: The results of this study identified that the application of $K M C$ in premature infants with HHHFN can accelerate the weaning process of oxygen therapy compared to infants who do not do KMC $(p<0,001)$. Therefore, nurses assigned to the neonatal care room should apply KMC to the HHHFNattached infants so that the they can reduce the duration of HHHFN use and decrease the length of stay in the hospital.

Keywords : Preterm infant; heated humified high flow nasal; kangaroo mother care,

How to Cite: Caswini, N., Rustina, Y., \& Efendi, D. (2021). Perawatan Metode Kanguru (PMK) dapat mempercepat proses penyapihan penggunaan High Flow Nasal (HFN) pada bayi prematur. NURSCOPE: Jurnal Penelitian dan Pemikiran Ilmiah Keperawatan, 7 (1), 1-5
\end{abstract}




\section{PENDAHULUAN}

Masalah pernapasan menempati urutan pertama sebagai penyebab kematian dan kecacatan pada bayibayi prematur (Shapiro-Mendoza et al., 2013). Data statistik global menunjukkan bahwa penyebab utama bayi-bayi prematur memerlukan perawatan dalam bulan pertama kehidupan adalah masalah respirasi, baik yang disebabkan oleh infeksi maupun yang disebabkan oleh faktor fisik-mekanik (Zeitlin et al., 2016). Kebutuhan akan oksigen dan alat bantu pernapasan pada bayi prematur lebih besar pada kelahiran prematur di usia gestasi kurang dari 30 minggu (Zeitlin et al., 2016).

Pemberian terapi oksigenasi pada gangguan pernapasan akut dinilai signifikan dalam memperbaiki fungsi dan kapasitas paru pada bayi prematur (Noripour et al., 2017). Salah satu terapi oksigenasi yang efektif untuk mengatasi gangguan pernapasan akut pada neonatus adalah dengan menggunakan Neonatal Continuous Positive Airway Pressure (NCPAP) atau Bubble CPAP. Sedangkan penggunaan terapi oksigen dalam bentuk Heated Humidified High Flow Nasal (HHHFN) merupakan salah satu terapi untuk gangguan pernapasan ringan hingga sedang tanpa menimbulkan komplikasi barotrauma pada bayi prematur (Roberts et al., 2016).

Pemberian HHHFN dapat dikombinasikan dengan intervensi lain diantaranya dengan perawatan metode kanguru (PMK), hal ini dapat menurunkan angka mortalitas dan morbiditas pada bayi prematur (Seidman et al., 2015). PMK memfasilitasi ibu dan bayi untuk melakukan kontak kulit dengan kulit yang dapat menstabilkan fungsi fisiologis tubuh bayi prematur serta memberikan kenyamanan dan pengaruh positif pada perkembangan sistem saraf bayi. Penelitian lain menyebutkan bahwa bayi prematur yang segera mendapatkan intervensi PMK menunjukkan perbaikan kondisi klinis serta mempersingkat waktu perawatan (Purushotham \& Nagesh, 2016). Purushotam dan Nagesh (2016) juga mengatakan bahwa PMK aman dilakukan untuk bayi prematur yang mendapat dukungan alat bantu napas dengan keberhasilan weaning HHHFN lebih cepat sebesar $89,4 \%$ dan pada NCPAP sebesar $68,4 \%$.

Berdasarkan data dari bayi prematur yang dirawat di ruang perawatan neonatologi RSCM bahwa sekitar 48,4\% mengalami gangguan pernapasan dan hampir sekitar 27,6 \% menggunakan alat bantu napas HHHFN. Berdasarkan hasil dari latar belakang tersebut, peneliti tertarik melakukan penelitian mengenai penerapan PMK pada bayi prematur yang terpasang HHHFN dengan masalah adaptasi respirasi agar dapat membuktikan bahwa PMK sangat berpengaruh untuk proses weaning HHHFN.

\section{METODE}

Desain yang digunakan dalam penelitian ini adalah quasi experiment pada bulan Februari-April 2018 di NICU RSUPN dr. Cipto Mangunkusumo Jakarta. Sampel diambil secara consecutive sampling dengan pretest-postest design dengan total sampel sebanyak 44 bayi yang terbagi menjadi 22 bayi untuk kelompok intervensi dan 22 bayi untuk kelompok kontrol, dengan kriteria inklusi bayi lahir dengan usia gestasi 28-36 minggu, berat badan bayi antara 1000-<2500 gram, dan terpasang alat bantu napas HHHFN; sedangkan kriteria eksklusi adalah bayi dengan kelainan kongenital dan ibu atau pengganti ibu yang tidak melakukan PMK. Tujuan rancangan penelitian ini adalah untuk mengidentifikasi dampak aplikasi PMK terhadap durasi penggunaan HHHFN pada bayi prematur dengan masalah distres napas. Kelompok intervensi adalah bayi prematur yang terpasang alat bantu napas HHHFN dan mendapatkan perlakuan PMK lebih dari 3 hari sedangkan pada kelompok control tidak melakukan PMK. Uji statistik T-test tidak berpasangan dengan menggunakan program komputer dilakukan untuk mengukur perbedaan rerata durasi penggunaan HHHFN antar kelompok. 


\section{HASIL DAN PEMBAHASAN}

Rerata usia gestasi pada kelompok intervensi adalah 31,68 minggu, sedangkan pada kelompok kontrol adalah 32,59 minggu. Usia koreksi rerata pada kelompok intervensi adalah 33,36 minggu, sedangkan pada kelompok kontrol adalah 34,32 minggu. Rerata berat badan lahir pada kelompok intervensi adalah 1.487 gram, sedangkan pada kelompok kontrol rerata berat badan lahir bayi adalah 1.562 gram. Rerata berat badan bayi saat dilakukan PMK pada kelompok intervensi adalah 1.584 gram, sedangkan pada kelompok kontrol adalah 1.669 gram.

Tabel 1. Karakteristik demografis sampel $(n=44)$

\begin{tabular}{lllccc}
\hline \multicolumn{1}{c}{ Variabel } & Kelompok & (n) & Mean & SD & Min-Max \\
\hline Usia gestasi & Intervensi & 22 & 31,68 & 1,701 & $27-34$ \\
& Kontrol & 22 & 32,59 & 1,709 & $30-36$ \\
Usia koreksi & Intervensi & 22 & 33,36 & 1,620 & $29-36$ \\
& Kontrol & 22 & 34,32 & 1,287 & $32-36$ \\
Berat badan lahir & Intervensi & 22 & 1487,50 & 172,825 & $1080-1850$ \\
& Kontrol & 22 & 1562,73 & 269,518 & $980-1910$ \\
Berat badan PMK & Intervensi & 22 & 1583,86 & 160,416 & $1120-1900$ \\
& Kontrol & 22 & 1669,09 & 151,057 & $1280-1900$ \\
\hline
\end{tabular}

Tabel 2 menunjukkan bahwa terdapat perbedaan bermakna antara kelompok intervensi dan kelompok kontrol terhadap perlakuan PMK dan lama pemakaian HHHFN dengan nilai $p=0,001 ; a<0,05$.

Tabel 2. Perbedaan rerata lama pemakaian HHHFN (hari) kelompok intervensi dan kelompok kontrol $(n=44)$

\begin{tabular}{ccccc}
\hline $\begin{array}{c}\text { Lama Pemakaian } \\
\text { HHFN }\end{array}$ & Mean & SD & Selisih rerata (CI 95\%) & p-Value \\
\hline $\begin{array}{c}\text { Intervensi } \\
\text { Kontrol }\end{array}$ & 6,64 & 1,270 & $3.73(0.336-7.90)$ & $0,001^{*}$ \\
\hline * & 11,32 & 5,746 & $2.55(6.998-12.093)$ & \\
\hline
\end{tabular}

*Uji Paired t test $a<0,05$

Hasil penelitian ini menunjukkan bahwa terdapat pengaruh perlakuan PMK dengan lama pemakaian HHHFN (Heated Humidified High Flow Nasal) pada bayi prematur. Berdasarkan hasil penelitian, bayi prematur yang termasuk dalam kategori kelompok intervensi (mendapatkan perlakuan PMK) menunjukkan durasi pemakaian HHHFN yang lebih singkat (kurang dari 10 hari). Hasil ini sesuai dengan penelitian yang dilakukan oleh Kalhor, Samieerad, Garshabi, Abadi dan Sefollah (2016) yang menyatakan bahwa bayi yang mendapatkan intervensi PMK menunjukkan peningkatan signifikan dalam status respirasi. PMK meningkatkan kemampuan bayi untuk bernapas secara spontan sehingga bayi lebih cepat dalam weaning oksigen (HHHFN dan BCPAP) (Kalhor, SamieeRad, Garshasbi, Abadi, Sefollah, 2016) .

Pemberian HHHFN dapat dikombinasikan dengan intervensi lain diantaranya dengan perawatan metode kanguru (PMK), hal ini dapat menurunkan angka mortalitas dan morbiditas pada bayi premature (Seidman et al., 2015). PMK memfasilitasi ibu dan bayi untuk melakukan kontak kulit dengan kulit yang dapat menstabilkan fungsi fisiologis tubuh bayi prematur serta memberikan kenyamanan dan pengaruh positif pada perkembangan sistem saraf bayi. Penelitian telah membuktikan bahwa kombinasi PMK dan HHHFN mempercepat waktu pelepasan oksigen (weaning) pada bayi prematur dengan RDS dibandingkan dengan terapi HHHFN tunggal.Penelitian ini juga menyebutkan bahwa bayi yang mendapatkan intervensi kombinasi PMK dan HHHFN menunjukkan status pernapasan yang cenderung stabil, ditandai dengan berkurangnya episode apnea serta kejadian desaturasi (Nimbalkar et al., 2012). 
Penelitian lain menyebutkan bahwa bayi prematur yang segera mendapatkan intervensi PMK menunjukkan perbaikan kondisi klinis serta mempersingkat waktu perawatan (Purushotham \& Nagesh, 2016). Penelitian ini menunjukkan bahwa PMK aman dilakukan untuk bayi prematur yang mendapat dukungan alat bantu napas dengan keberhasilan weaning HHHFN lebih cepat sebesar $89,4 \%$ dan pada NCPAP sebesar $68,4 \%$. Penelitian ini juga menekankan bahwa penggunaan HHHFN saat PMK lebih efektif jika dibandingkan dengan NCPAP karena risiko bergesernya kanul HHHFN lebih kecil jika dibandingkan dengan NCAP. Penelitian lain juga menyatakan bahwa PMK efektif dilakukan untuk bayi yang terpasang HHHFN dan memberikan pengaruh positif berupa penurunan kebutuhan oksigen, kestabilan status pernapasan, mempercepat weaning HHHFN dan mempersingkat waktu perawatan bayi (Bieleninik \& Gold, 2014; Purushotham \& Nagesh, 2016).

Berdasarkan penelitian yang telah dilakukan penulis bahwa penerapan PMK pada bayi yang terpasang HHHFN dapat menjadi inovasi asuhan keperawatan khususnya dalam memenuhi kebutuhan oksigenasi bayi prematur. Perawat neonatus yang bertugas di ruang perawatan perinatologi mempunyai peran penting dalam menerapkan keberhasilan penggunaan HHHFN dengan intervensi PMK supaya bayi prematur lebih cepat di sapih dari alat bantu napas tersebut, hal ini mengingat dampak dari pemakaian oksigen yang terlalu lama akan berakibat menimbulkan komplikasi yang sering muncul pada bayi prematur.

\section{SIMPULAN DAN SARAN}

PMK memiliki dampak positif terhadap perecepatan penyapihan penggunaan HHFN. Hasil penelitian ini semakin melengkapi bukti kemanfaatan PMK pada bayi prematur dengan gangguan pernapasan. Melalui hasil penelitian ini hendaknya rekan sejawat, khususnya perawat tidak perlu takut dalam mengaplikasikan PMK pada bayi prematur dengan distres pernapasan dengan kondisi stabil. Perawat kepala juga dapat berpartisipasi dalam mendorong aplikasi PMK pada bayi prematur dengan distres napas melalui pembuatan SPO yang akan menjadi panduan pelaksanaan PMK di NICU.

\section{DAFTAR PUSTAKA}

Bieleninik, Ł., \& Gold, C. (2014). Early intervention for premature infants in neonatal intensive care unit. Acta Neuropsychologica, 12(2), 185-203. https://doi.org/10.5604/17307503.1111845

Kalhor, M., SamieeRad, F., Garshasbi, M., Abadi, Z., Sefollah, S. (2016). Evaluating the effect of mother baby skin-to-skin care on neonatal outcomes in preterm infants. J Shahid Sadoughi Univ Med Science, 24(5), 375-386.

Nimbalkar, S., Tandon, R., \& Chaudhary, N. (2012). 1809 Reduced Duration of CPAP in Preterm Babies Receiving Kangaroo Care within an Hour of Birth - Randomized Trial. Archives of Disease in Childhood, 97(Suppl 2), A512-A512. https://doi.org/10.1136/archdischild-2012-302724.1809

Noripour, S., Molaei, A., Bandari, R., Emadi, A., Far, S. M. F., \& Forozeshfard, M. (2017). Comparison of the results of simultaneous surfactant administration and nasal continuous positive airway pressure (INSURE) and Non-administration of surfactant for the treatment of infants with respiratory distress syndrome. Journal of Comprehensive Pediatrics, 8(1). https://doi.org/10.5812/compreped.37462

Purushotham, S., \& Nagesh, N. (2016). Feasibility and efficacy of early KMC in very low birth weight babies 
receiving noninvasive respiratory care in NICU: is it the way forward in resource limited setting? International Journal of Contemporary Pediatrics, 3(4), 1156-1159. https://doi.org/10.18203/23493291.ijcp20163103

Roberts, C. T., Owen, L. S., Manley, B. J., Frøisland, D. H., Donath, S. M., Dalziel, K. M., Pritchard, M. A., Cartwright, D. W., Collins, C. L., Malhotra, A., \& Davis, P. G. (2016). Nasal High-Flow Therapy for Primary Respiratory Support in Preterm Infants. New England Journal of Medicine, 375(12), 11421151. https://doi.org/10.1056/nejmoa1603694

Seidman, G., Unnikrishnan, S., Kenny, E., Myslinski, S., Cairns-Smith, S., Mulligan, B., \& Engmann, C. (2015). Barriers and enablers of Kangaroo mother care practice: A systematic review. PLOS ONE, 10(5), 120. https://doi.org/10.1371/journal.pone.0125643

Shapiro-Mendoza, C., Kotelchuck, M., Barfield, W., Davin, C. A., Diop, H., Silver, M., \& Manning, S. E. (2013). Enrollment in early intervention programs among infants born late preterm, early term, and term. Pediatrics, 132(1). https://doi.org/10.1542/peds.2012-3121

Zeitlin, J., Manktelow, B. N., Piedvache, A., Cuttini, M., Boyle, E., Van Heijst, A., Gadzinowski, J., Van Reempts, P., Huusom, L., Weber, T., Schmidt, S., Barros, H., Dillalo, D., Toome, L., Norman, M., Blondel, B., Bonet, M., Draper, E. S., \& Maier, R. F. (2016). Use of evidence based practices to improve survival without severe morbidity for very preterm infants: Results from the EPICE population based cohort. BMJ (Online), 354, 1-10. https://doi.org/10.1136/bmj.i2976 